دراسة لبعض أنشطة المر أة البدوية فى تسويث المنتجات المحلية بالساحل الشمالى الغربى عاشورة حسين محمد مرسى مصطفى لطفى عبد العزيز الإيز

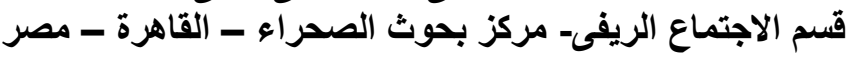

المستخلص استهدف البحث التعرف على أنواع المنتجات المحلية التى تقوم المر أه البدوية بتسويقها، و أمساكن

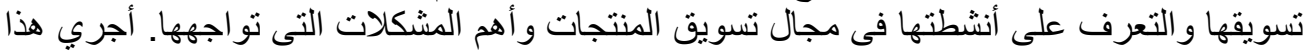

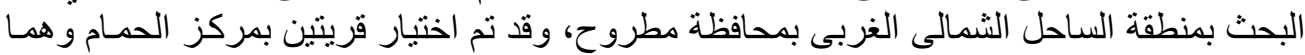

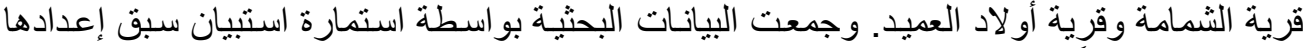

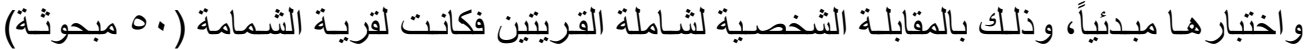

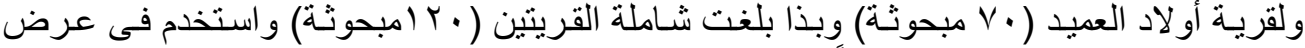

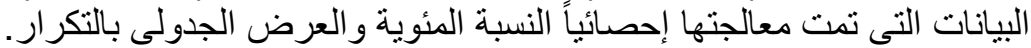

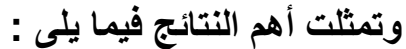

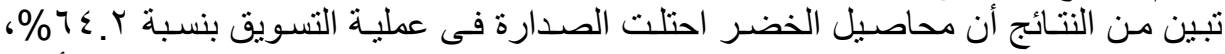

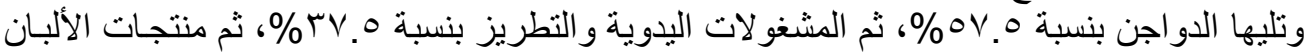

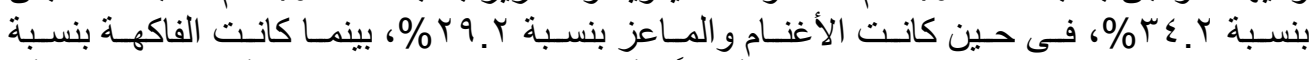

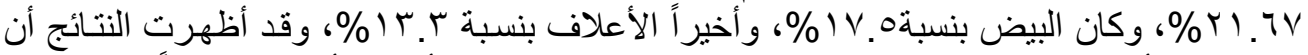

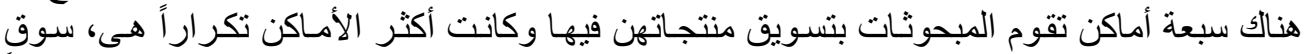
القرية، ثم البيع للوسيط، يليه سوق المركز، ثم تـاجر الجملـة ثم معـارض الجمعيـات الأهلية و أخيراً

أوضحت النتائج أن المر أة البدوية تقوم بعشرة أنشطة لتسويق منتجاتها المحلية، وكان أهمها البيع بالمنزل.

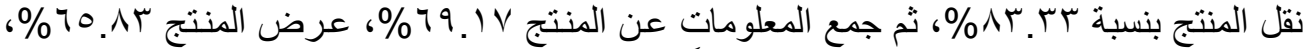

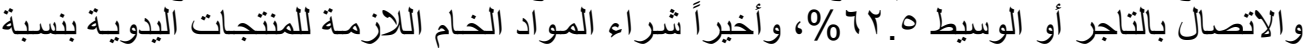

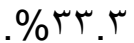

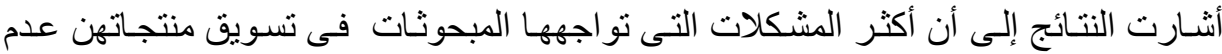

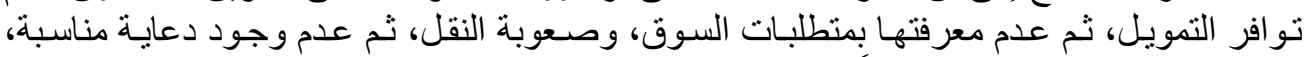

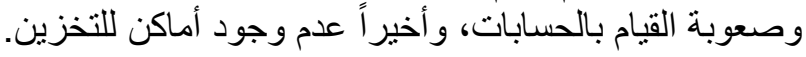

المقدمة والمشكلة البحثية:

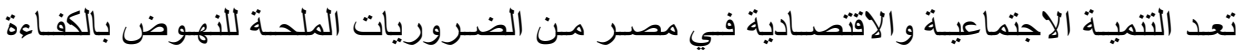

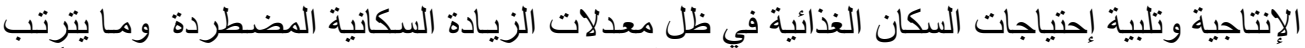

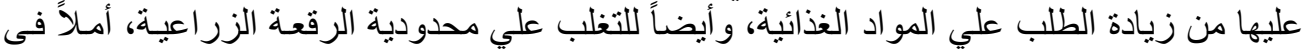

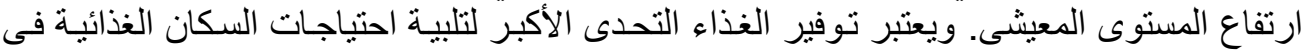

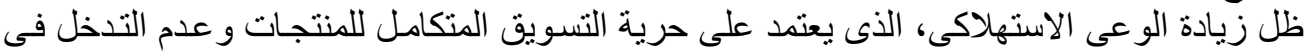

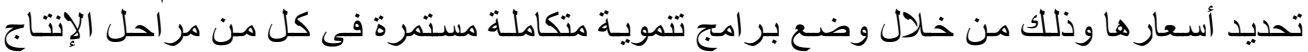

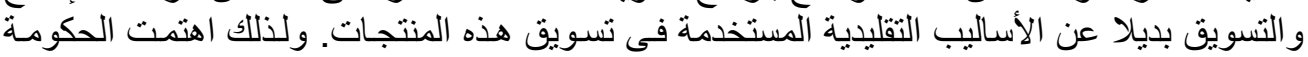

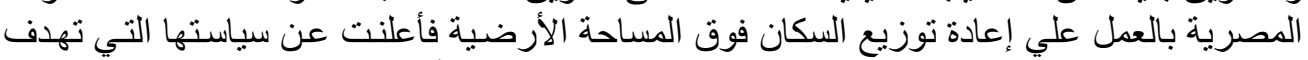

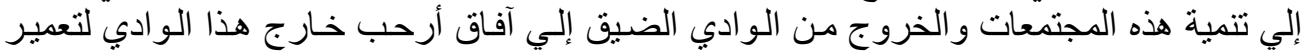

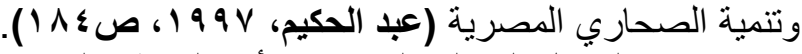

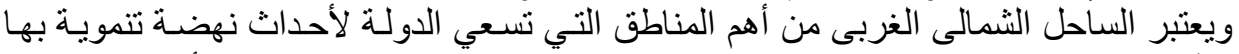
و تفعيل آليات التنمية عن طريق إستصلاح و استززر اع مسـاحات جديدة منـه، وتطوير أسـاليب الإنتاج

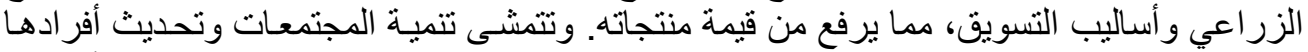

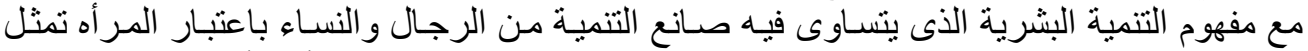

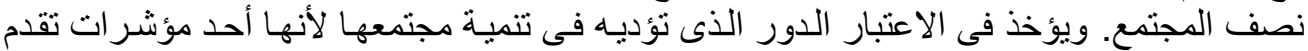

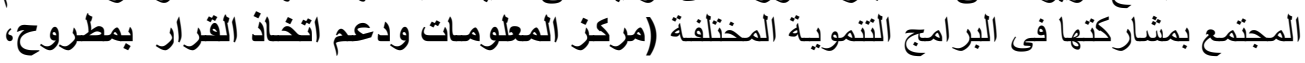

Fayoum J. Agric. Res. \& Dev., Vol.24, No.2, July, 2010 


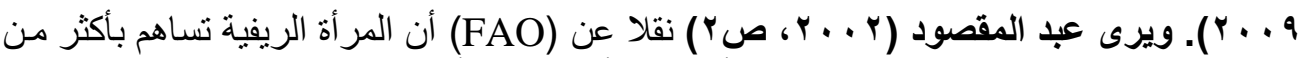

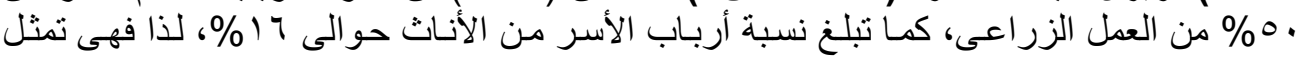

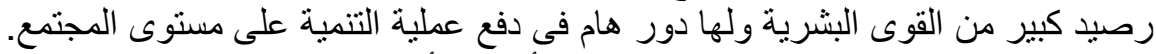

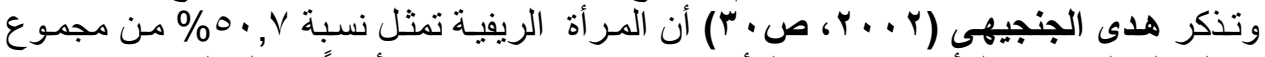

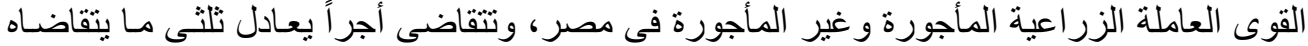

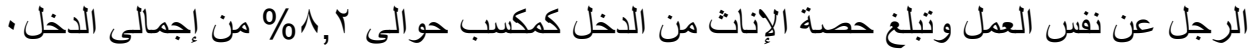

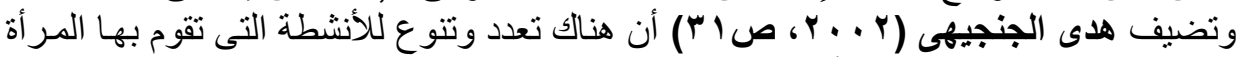

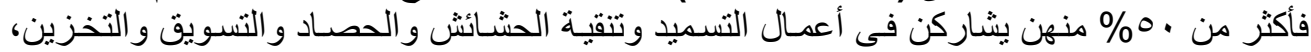

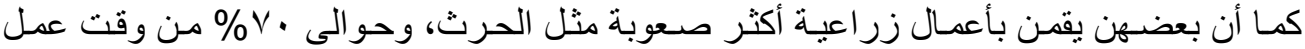

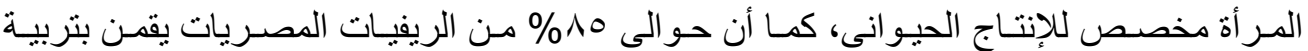

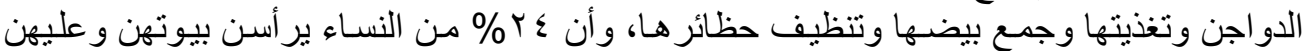
اتخاذ قرار ات يومية فى نو احنى متعددة.

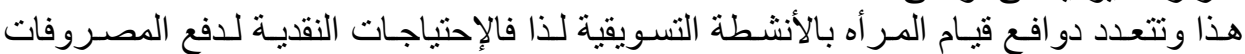

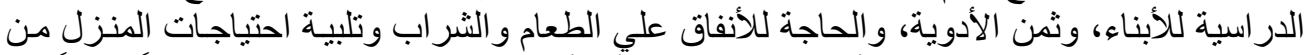

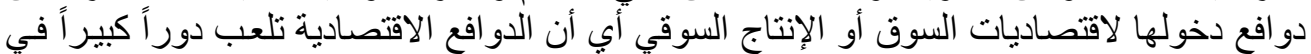

قيام الريفيات بالعملية التسويقية (Zimmermann, 1982, p13)

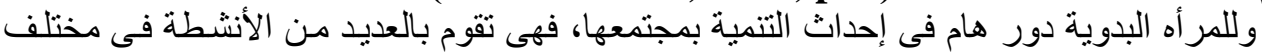

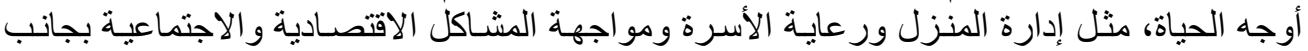

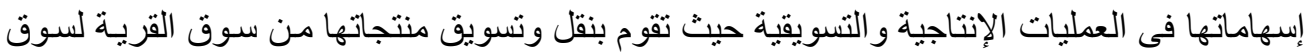

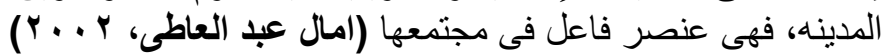

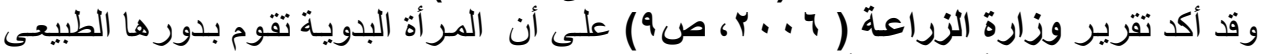

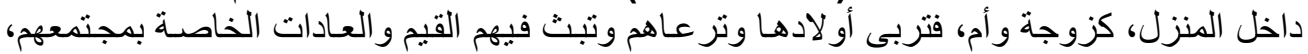

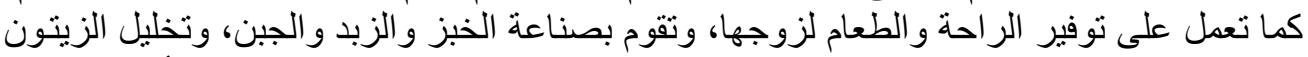

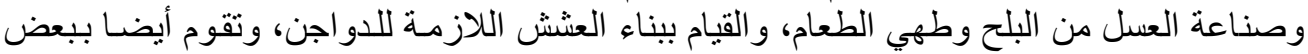

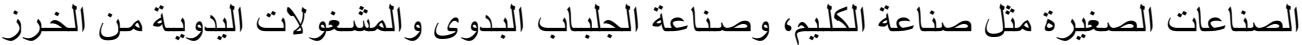

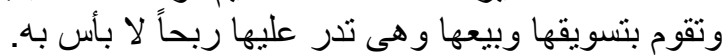

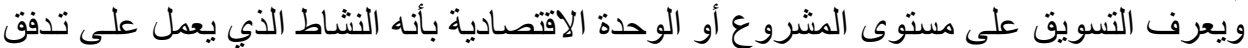

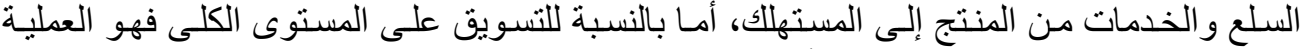

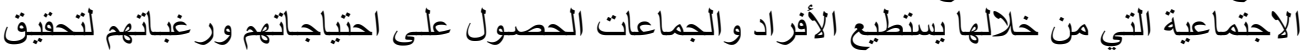

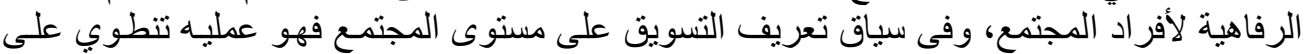

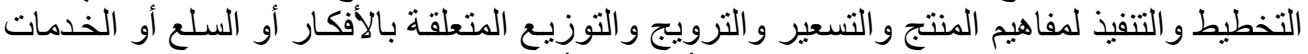

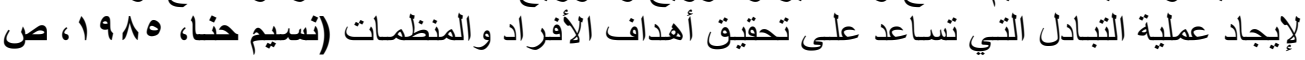

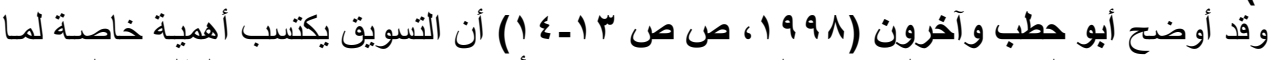

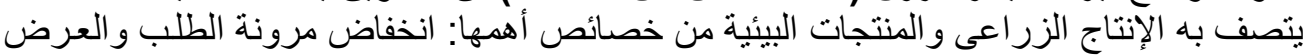

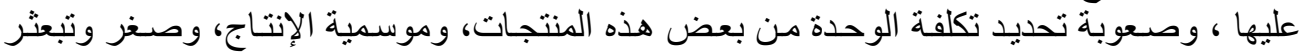

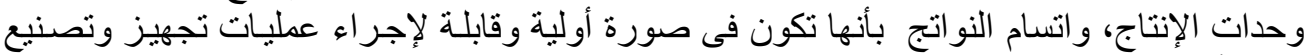

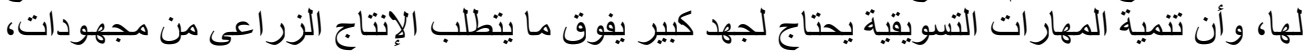

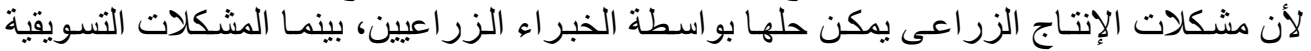

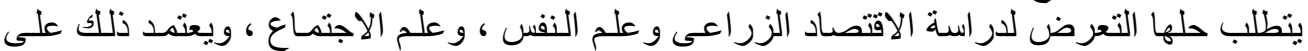

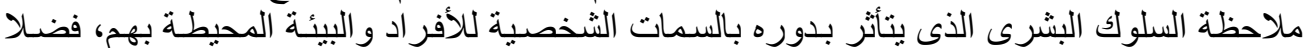

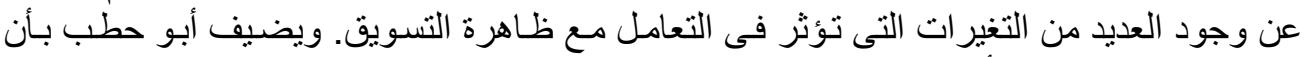

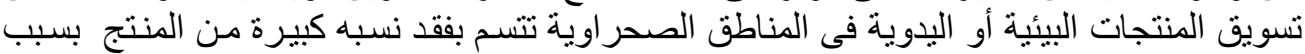

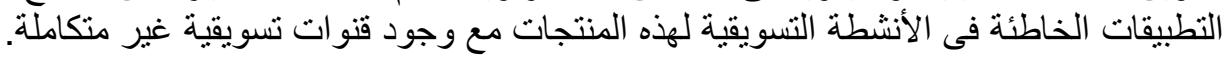

Fayoum J. Agric. Res. \& Dev., Vol.24, No.2, July, 2010 


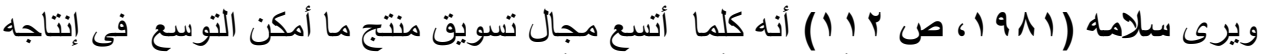

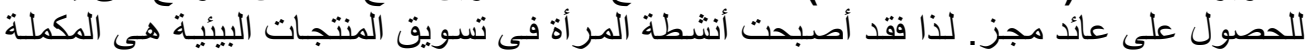

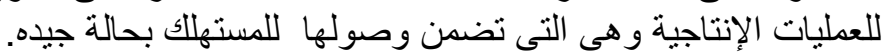

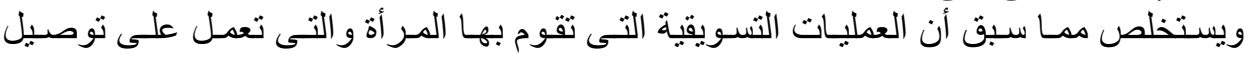

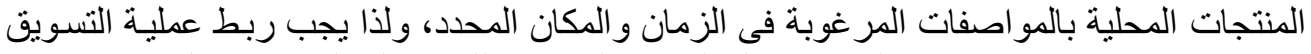

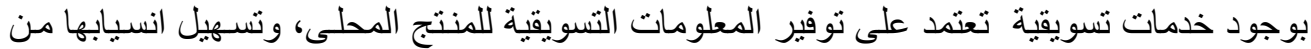

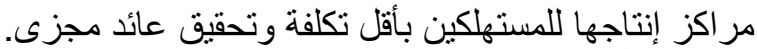

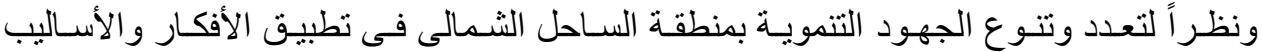

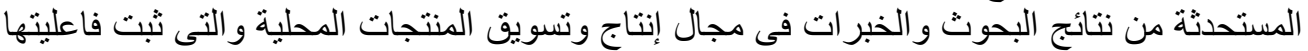

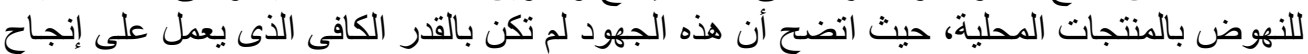

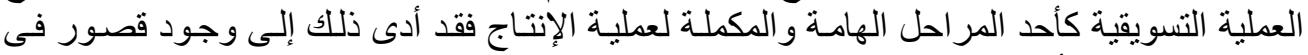

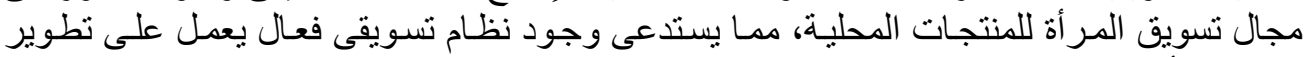

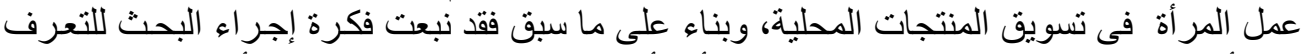

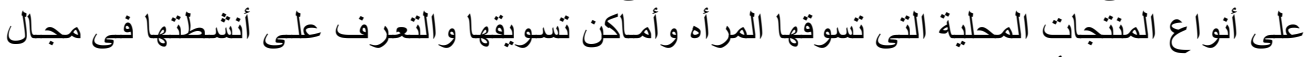

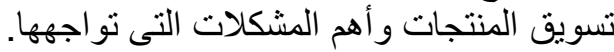

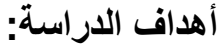
ا ـ التعرف على أنواع المنتجات المبات المحلية التى تقوم المر أة بتسويقها فى منطقة الدراسة.

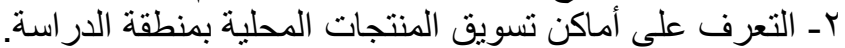

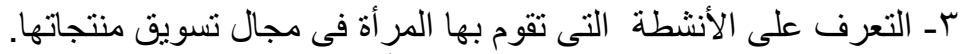
ع ـ التعرف على المشكلات التى تو اجه المر أة في تسويق المن المنتجات المحلية.

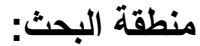

إجرى هذا البحث بمنطقة الساحل الثمالى الغربى لجمهورية مصر العربية التى تمتد من الكيلو

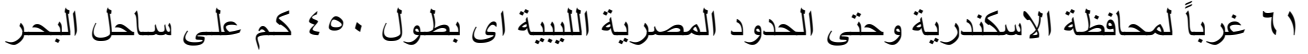

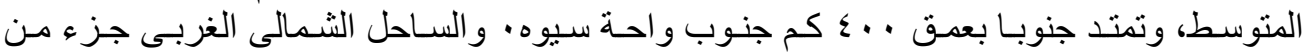

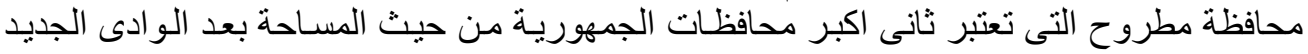

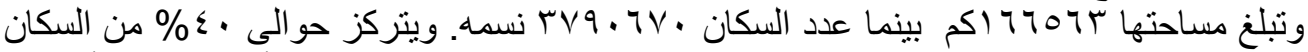

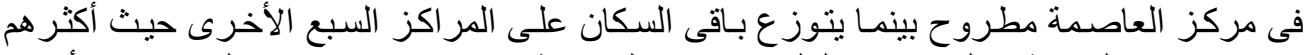

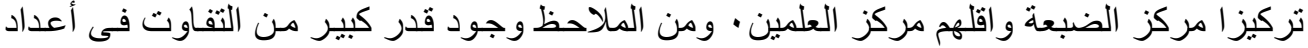

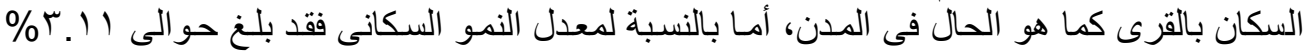

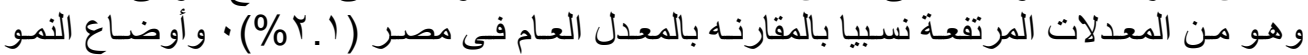

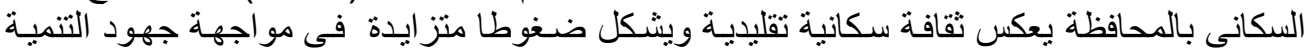

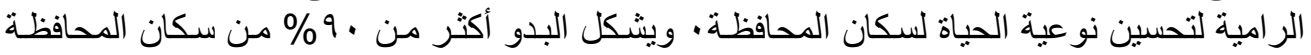

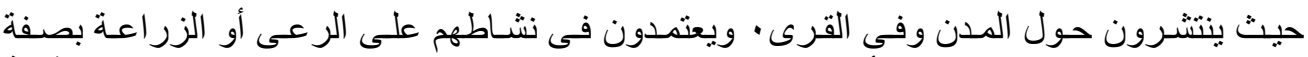

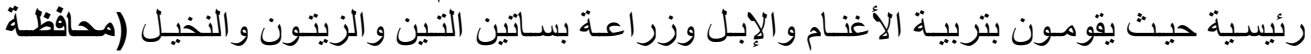

ولتحديد منطقة البحث تم اختيار مركز الحمام لإجر اء البحث بـاه ويمتئد بطول

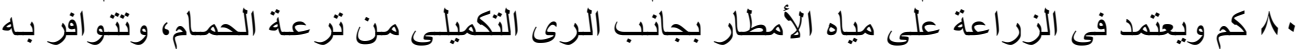

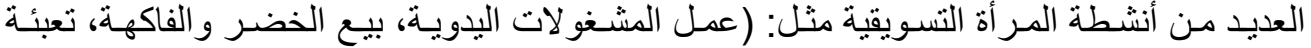

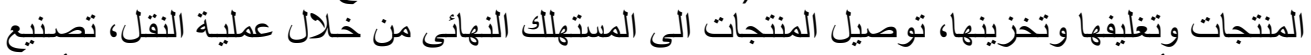

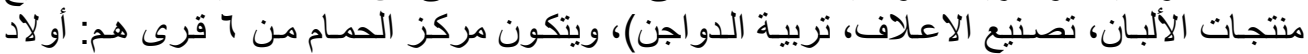

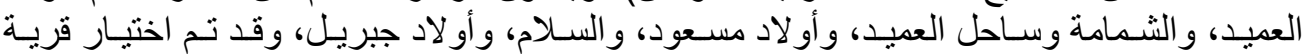

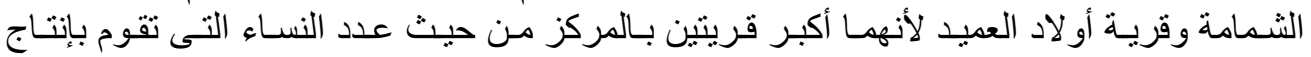
وتسويق المنتجات المحلية.

Fayoum J. Agric. Res. \& Dev., Vol.24, No.2, July, 2010 
شـاملة البحث: تمثلت شـاملة البحث للمر أة البدويـة بقريـة أولاد العميد، وقريـة الثمامة حيث بلغت

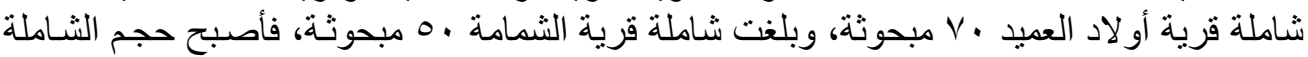

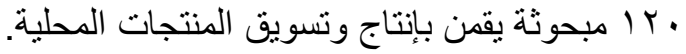

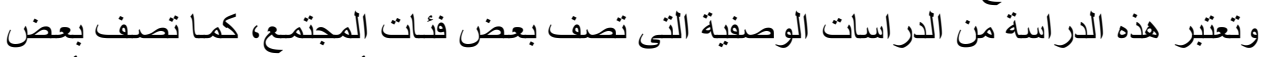

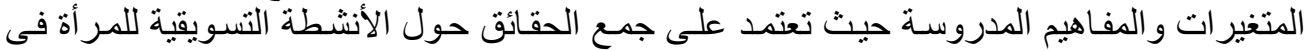

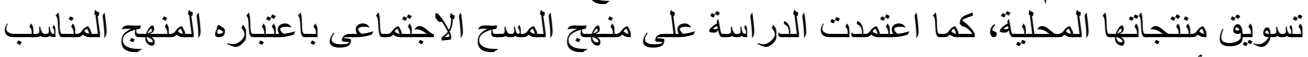

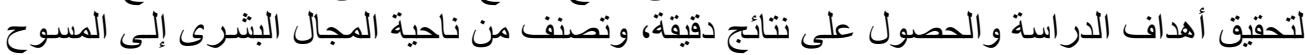

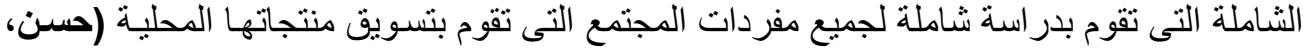

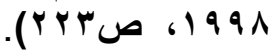

أداة جمع البيانات

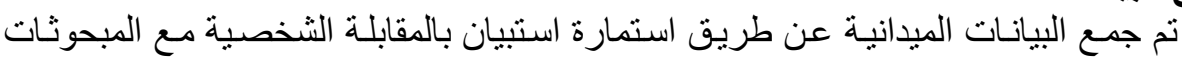

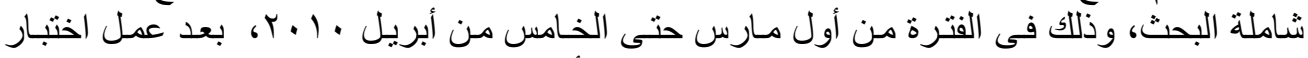

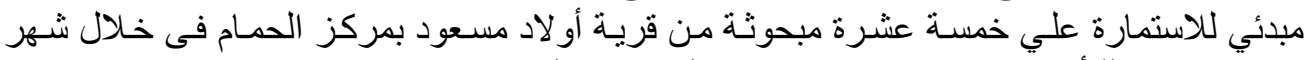

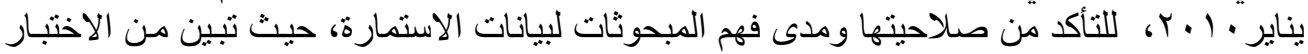

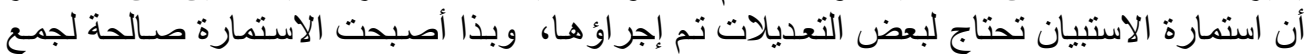

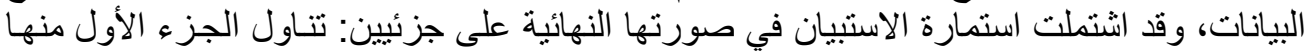

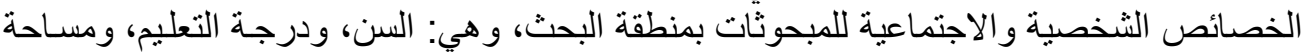

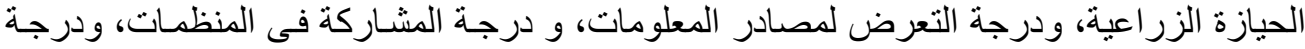

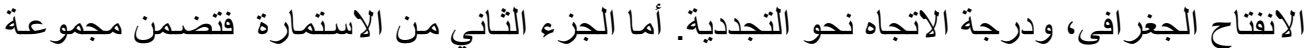

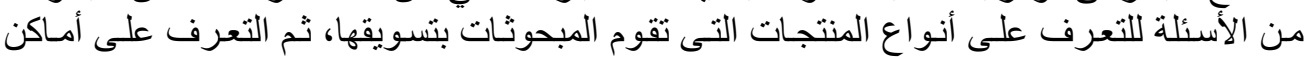

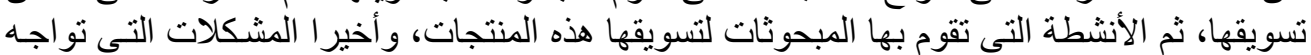

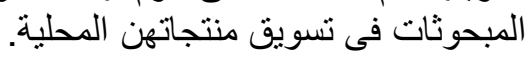

أساليب التحليل الاحصائى: استخدم في تحليل بيانات الدراسـة العرض الجدولى بـالتكر ارات و النسبة ا ـ السن: نم قياس هذا المتغير بسؤ ال المبحوثة عن عن عدد سنوات عمر هـا لأقرب سنة ميلاديـة وقت

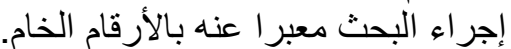

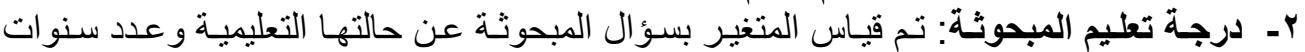

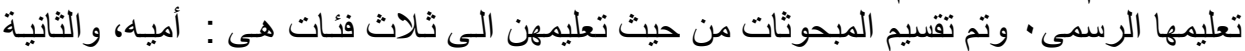

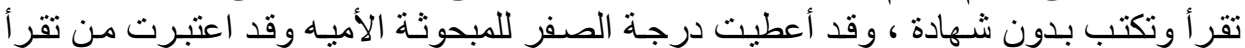

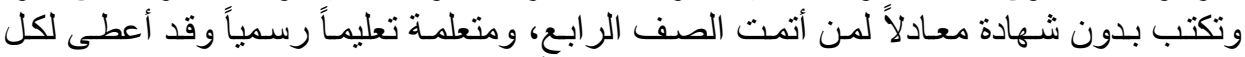

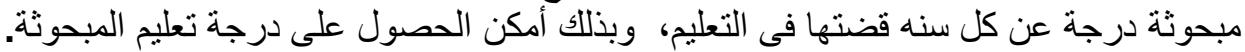

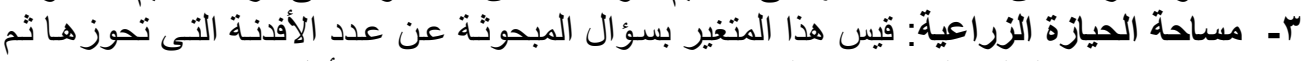

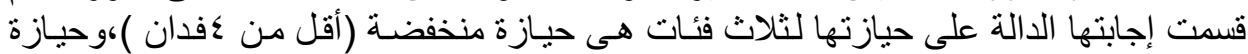

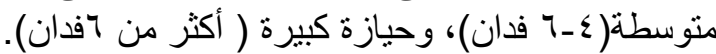

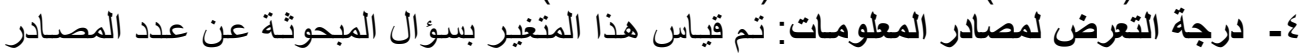

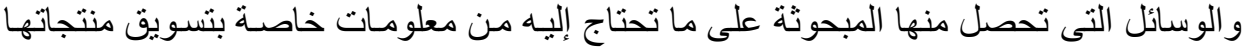

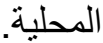

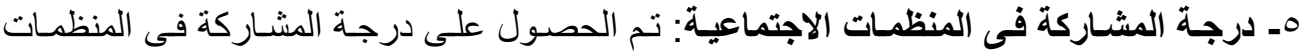

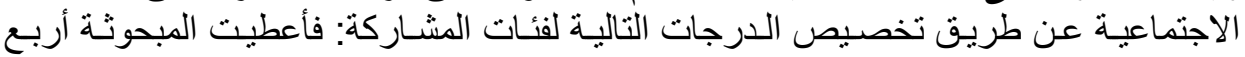

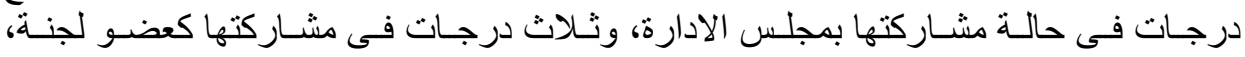

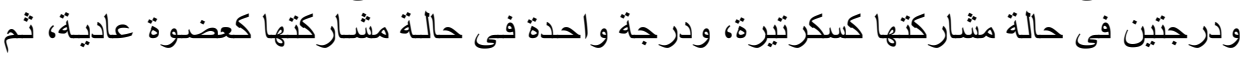

جمعت درجات مشاركتها لتعبر عن الدرجة الإجمالية لمشاركتها فى المنظمات الاجنة الاجتماعية.

Fayoum J. Agric. Res. \& Dev., Vol.24, No.2, July, 2010 
rq

7 - درجة الانفتاح الجغرافى: قيس هذا المتغير بسؤال المبحوثه عن انفتاحها الجغر افى، و أعطيت

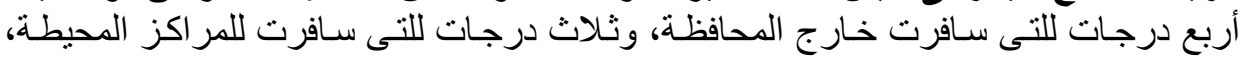

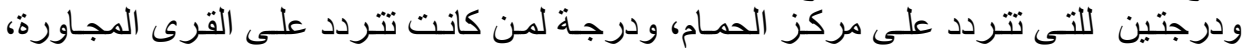

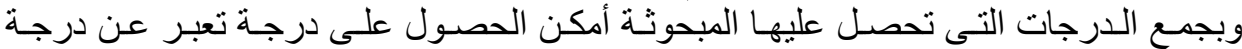

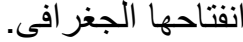

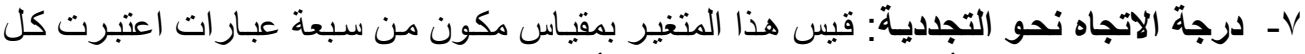

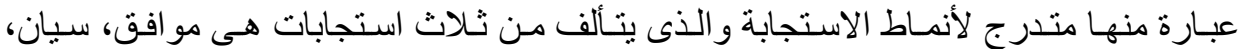

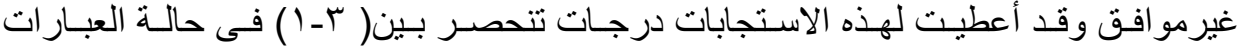

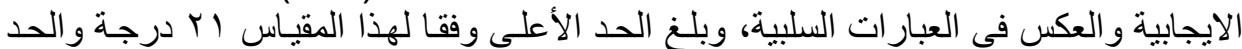

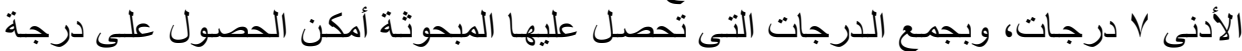

تعبر عن اتجاه المبحوثات نحو التحو التجدية في في الأنشطة التسويقية.

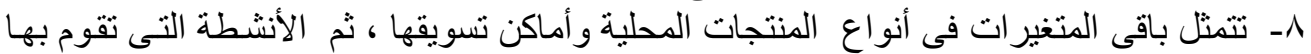

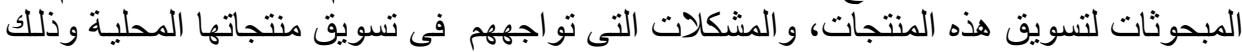

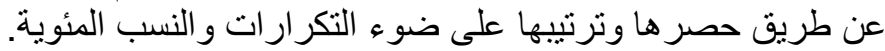

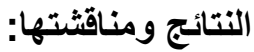
اولا : وصف الخصائص الثخصية للمبحوثات:

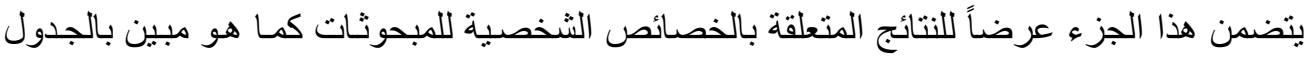

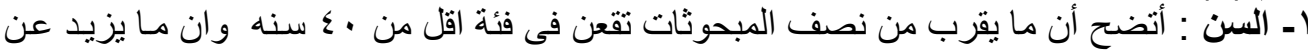

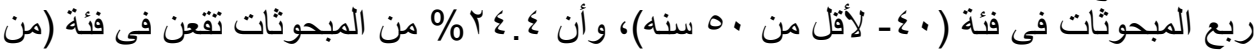

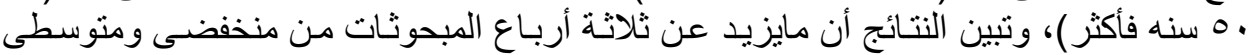

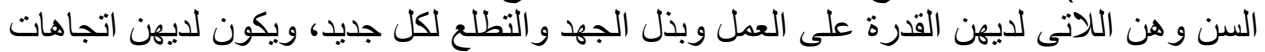

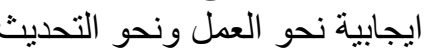

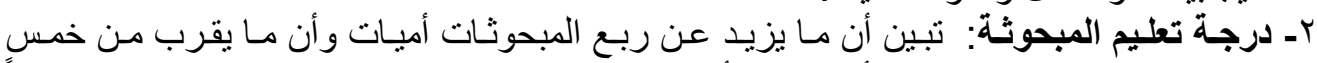

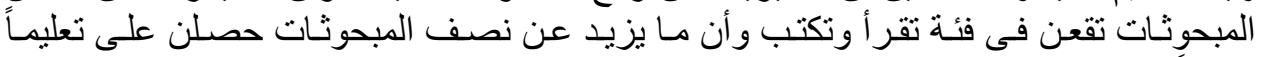

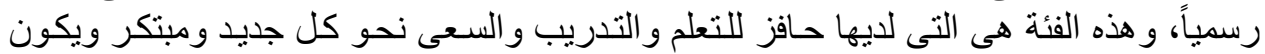
لايهن الطموح و العمل على رفئ رفع مستوى أسر هن.

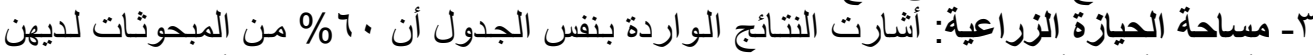

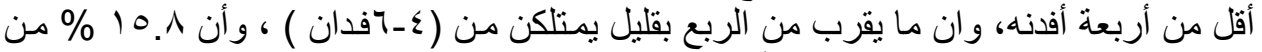

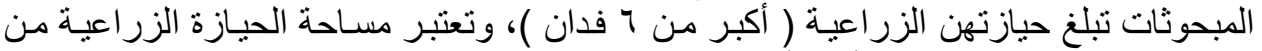

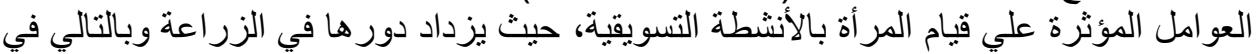

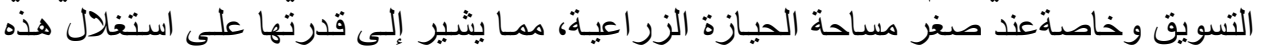

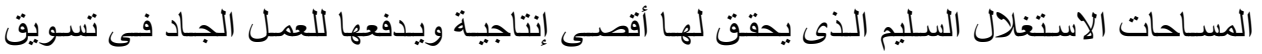
منتجاتها .

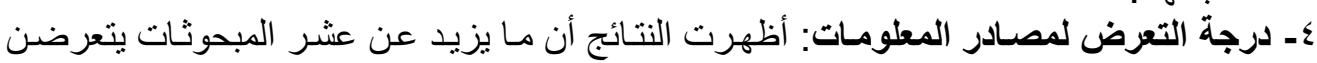

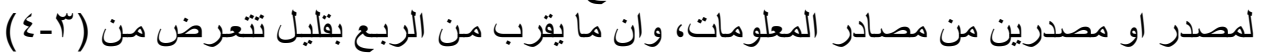

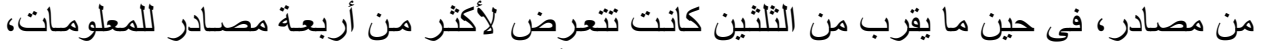

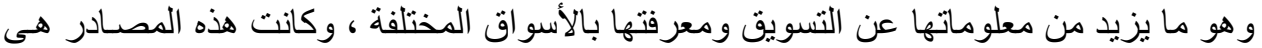

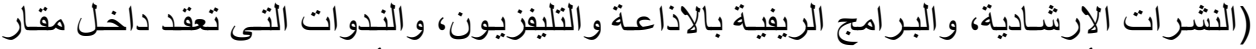

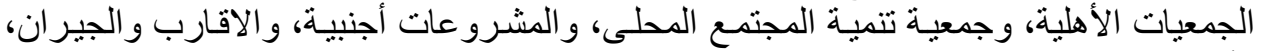

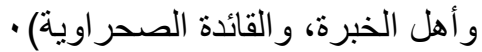

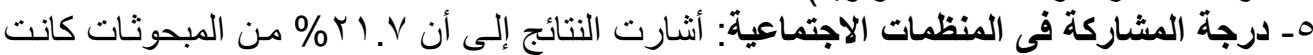

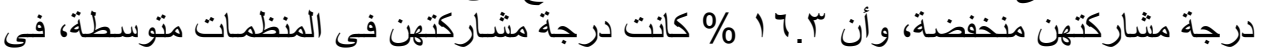

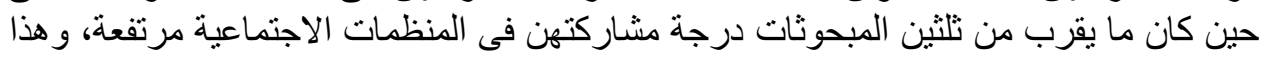

Fayoum J. Agric. Res. \& Dev., Vol.24, No.2, July, 2010 
rv

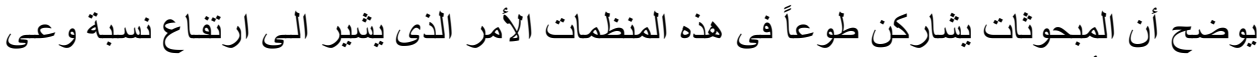

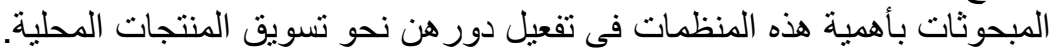

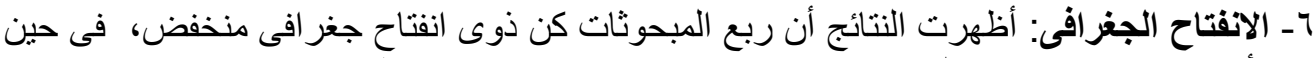

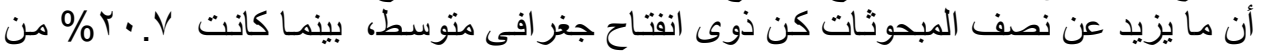

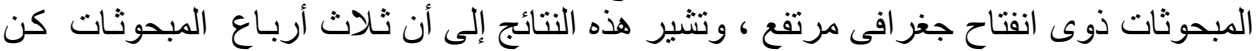

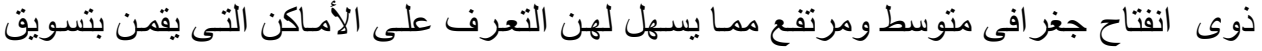

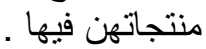

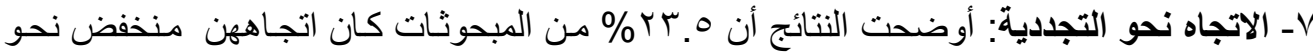

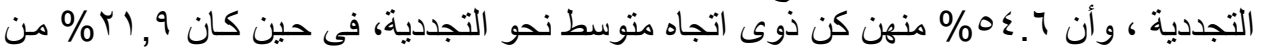

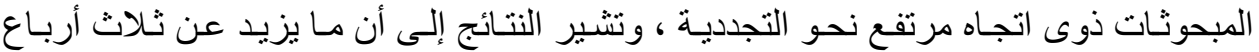

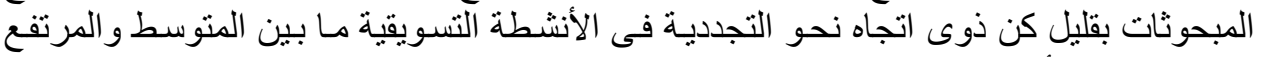

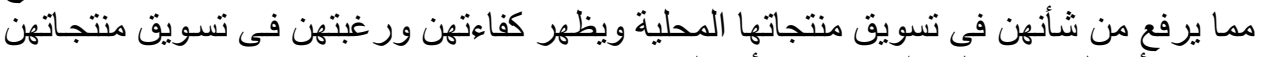
بصورة أفضل بما يعمل على تحسين أحون تصو الهن الاجتماعية والاقتصادية.

جدول رقم (1): توزيع المبحوثات وفقا للخصائص الشخصية والاجتماعية.

\begin{tabular}{|c|c|c|c|c|}
\hline$\%$ & ن = العدد & الفئـــــــــــات & الخصائص الثخدية & r \\
\hline $\begin{array}{l}\Sigma \Lambda . r r \\
r v .0 . \\
r \leqslant . I V\end{array}$ & $\begin{array}{l}01 \\
\text { ra } \\
r\end{array}$ & 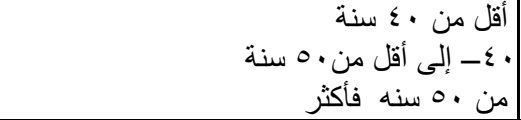 & الســـــن & 1 \\
\hline $\begin{array}{l}r V .0 . \\
I V .0 . \\
00 . .\end{array}$ & 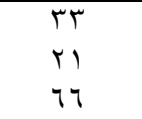 & أميةً & درجة تعليم المبحوثة & $r$ \\
\hline $\begin{array}{l}7 . \cdots \\
r \leq .4 . \\
10.1 .\end{array}$ & $\begin{array}{l}V Y \\
r 9 \\
19\end{array}$ & 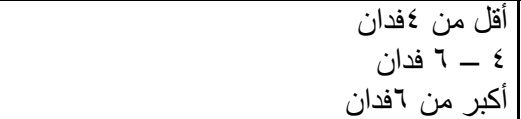 & مساحة الحيازة الزراعية & $r$ \\
\hline $\begin{array}{l}1.0 . \\
\text { r. } \\
70.1 .\end{array}$ & $\begin{array}{l}10 \\
r 7 \\
19\end{array}$ & 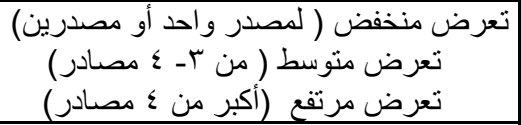 & | درجة التعرض لمصلادر | & $\varepsilon$ \\
\hline $\begin{array}{l}r . V \\
1 V .0 \\
7 . .1\end{array}$ & 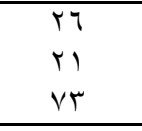 & 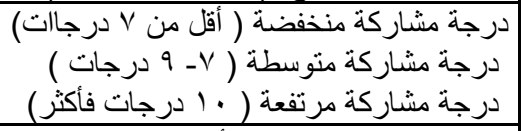 & المنظمات الاجتماعية & 0 \\
\hline 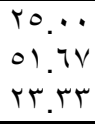 & 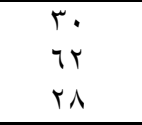 & 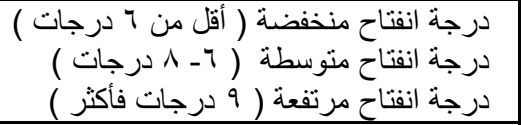 & |درجة الانفتاح الجغر افى | & 7 \\
\hline $\begin{array}{l}\text { r.IV } \\
\text { Or.o. } \\
\text { r.T. }\end{array}$ & $\begin{array}{l}4 \\
4 \\
4 \\
4\end{array}$ & 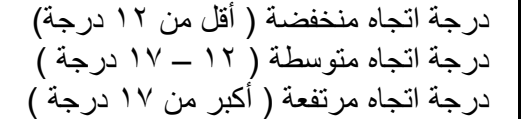 & درجة الاتجاه نحو & v \\
\hline
\end{tabular}

المصدر: جمعت وحسبت من استمارة الاستبيان.

ثانيا : : انواع المنتجات المحلية التتقوم المرأة بانتاجها وتسويقها

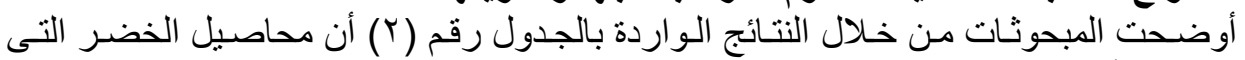

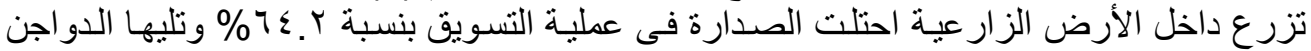

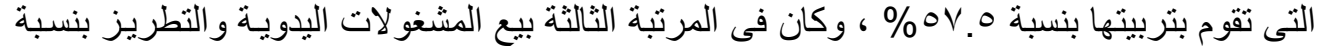

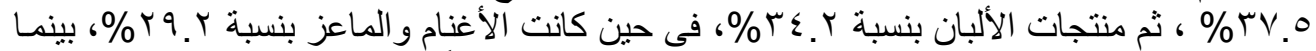

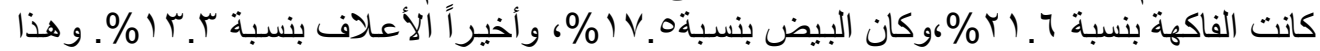

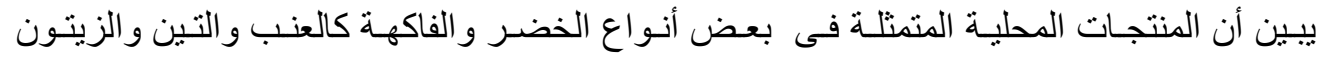

Fayoum J. Agric. Res. \& Dev., Vol.24, No.2, July, 2010 
r^

و النخيل و اللوز و الثعير و القمح و الطماطم و البسلة و الكوسة و الخضر الورقية، و المشغو لات اليدويـة

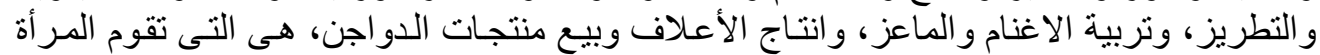

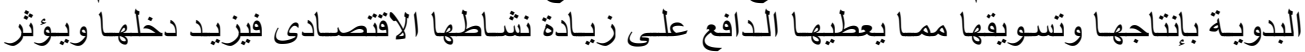

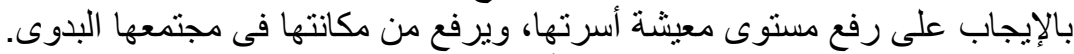

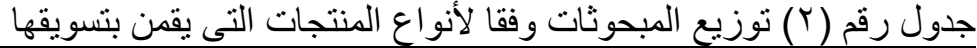

\begin{tabular}{|c|c|c|}
\hline$* * \%$ & العدد * & أنواع المنتجات \\
\hline $7 \varepsilon .17$ & $\overline{V V}$ & محاصبل الخضر \\
\hline ov. o. & 79 & أغنام وماعز \\
\hline Y1.74 & YT & فاكهة \\
\hline rV.O. & $\leqslant 0$ & مشغو لات يدوية \\
\hline$r \varepsilon .17$ & 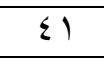 & تصنيع منتجات الألبان \\
\hline Y9.17 & ro & دو اجن وطيور \\
\hline 18.0. & YI & بيض \\
\hline ת & 17 & أعلاف \\
\hline
\end{tabular}
* * للمبحوثة الفرصة لأكثر من استجابة الإنة

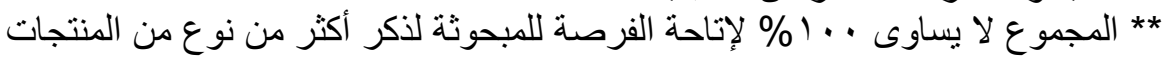

ثالثا : أنواع الأنثطة التى تقوم بها المراة البدوية لتسويق منتجاتها:

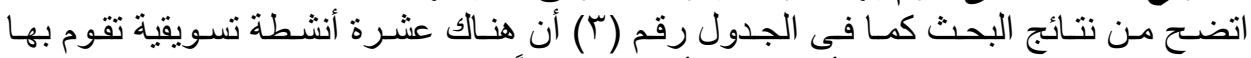

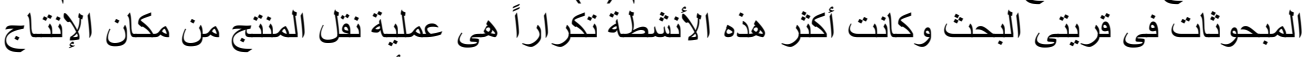

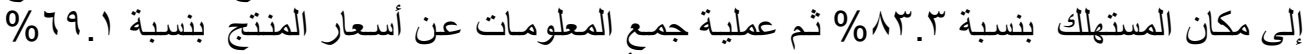

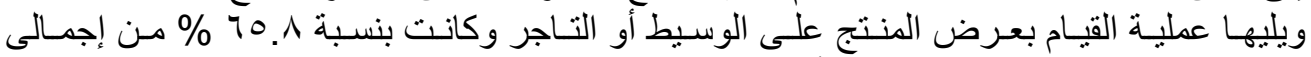

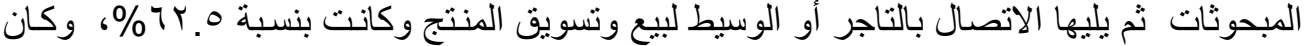

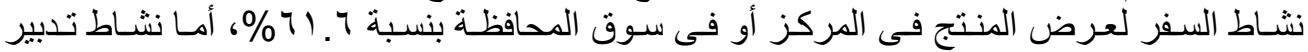

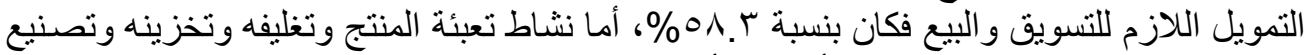

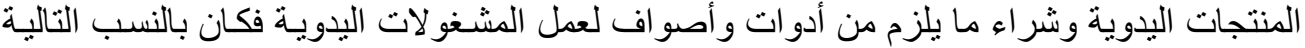

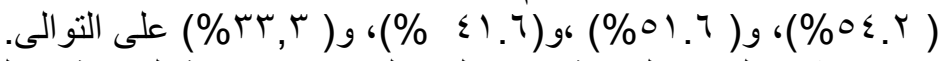

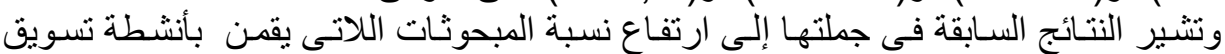

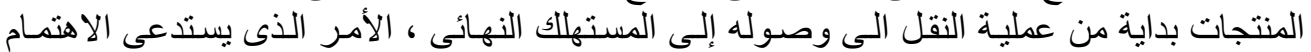

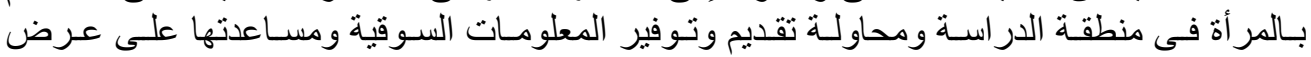

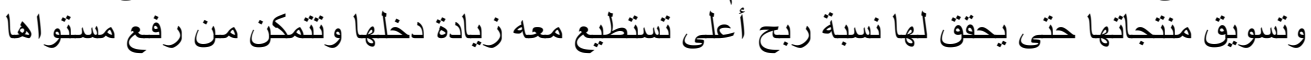

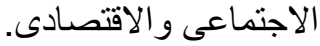

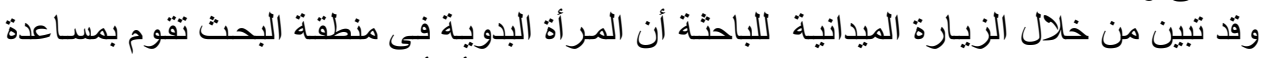

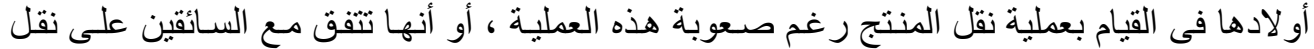

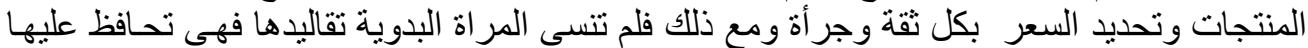
ولكنها فى نفس الوقت تتمكن من التعامل مع الغرباء .

\begin{tabular}{|c|c|c|}
\hline$* * \%$ & العدد * & أنواع الأنشطة \\
\hline (1) & $1 \cdots$ & عملية نقل المنتج \\
\hline 79.17 & $\Delta \mu$ & جمع المعلومات عن اسعار المنتج \\
\hline $70 . \wedge r$ & $\mathrm{Vq}$ & القيام بعرض المنتج \\
\hline Tr.o. & Vo & الاتصـال بالتاجر او الوسيط \\
\hline 71.77 & $V \varepsilon$ & السفر لعرض المنتج فى المركز او المحافظة \\
\hline
\end{tabular}

Fayoum J. Agric. Res. \& Dev., Vol.24, No.2, July, 2010 


\begin{tabular}{|c|c|c|}
\hline oᄉ.r. & $V \cdot$ & تدبير التمويل اللازم \\
\hline $0 \leqslant .1 \mathrm{~V}$ & 70 & تعبئة وتغليف المنتج \\
\hline $01.7 \mathrm{~V}$ & $7 r$ & التخزين \\
\hline$\varepsilon 1.7 \mathrm{~V}$ & 0. & تصنيع المنتجات \\
\hline מש. & $\varepsilon$. & شر اء المو اد الخام اللازمة للمنتجات اليدوية \\
\hline
\end{tabular}

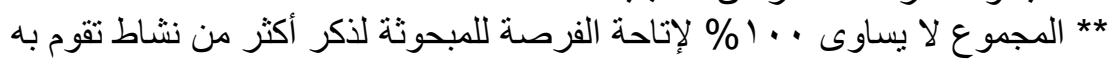
رابعا: توزيع المبحوثات وفقا للاهمية النسبية للاماكن التى يسوقن فيها المنتجات:

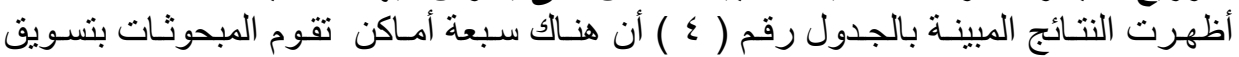

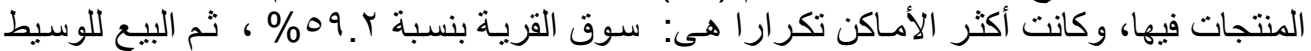

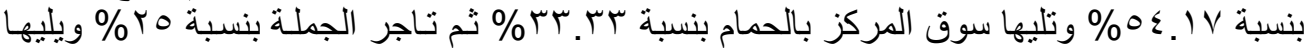

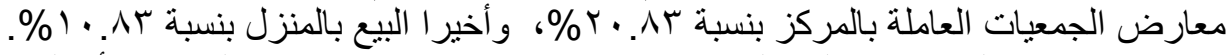

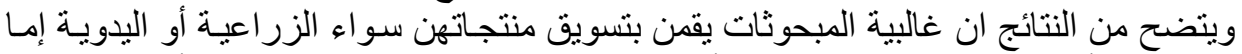
فى سوق القرية أو من خلال البيع للوسيط الأمر الذى يشير إلى تفضيل المبحوثات للأمساكن القريبه

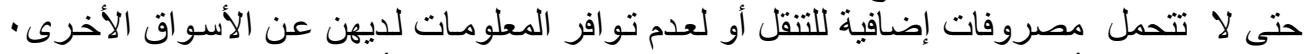

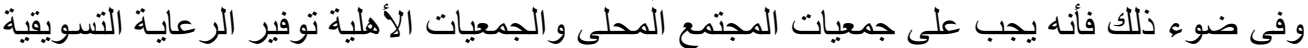

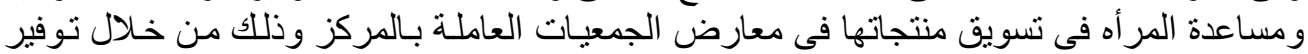

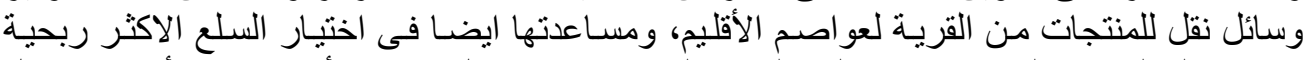

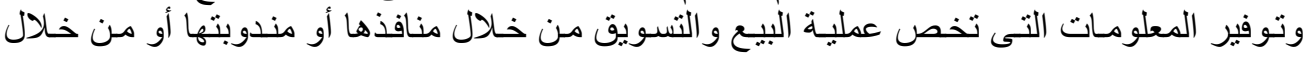

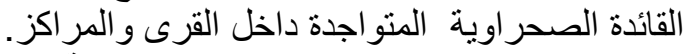

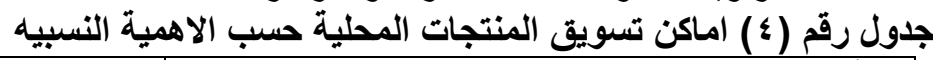

\begin{tabular}{|c|c|c|}
\hline ** $\%$ & * العدد & أماكن تسويق المنتجات \\
\hline $09.1 \mathrm{~V}$ & VI & سوق القرية \\
\hline $0 \leqslant .1 \mathrm{~V}$ & 70 & البيع للوسيط \\
\hline " & $\varepsilon$. & سوق المركز \\
\hline ro... & $r \cdot$ & تاجر الجملة \\
\hline$r \cdot . \Lambda r$ & ro & معارض الجمعيات العاملة بالمركز \\
\hline 1. 1. & Tr & الييع بالمنزل \\
\hline
\end{tabular}

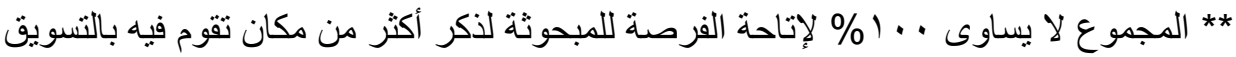

خامسا : المشكلات المتعلقة بتسويق المنتجات المحلية:

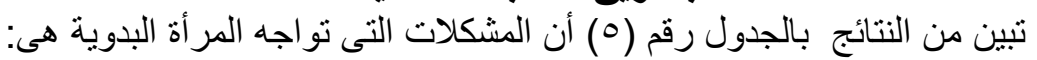

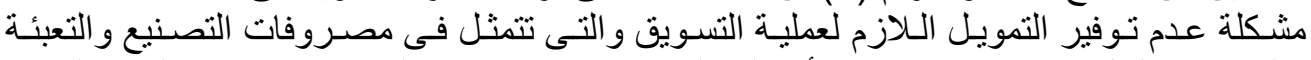

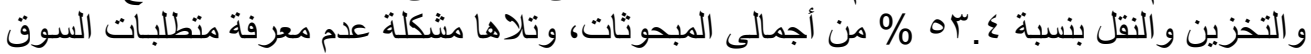

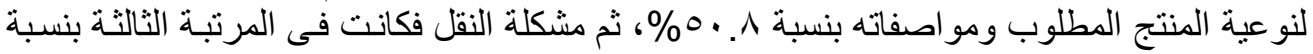

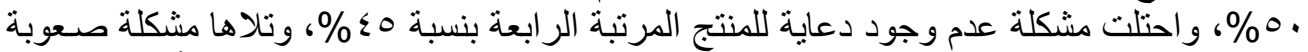

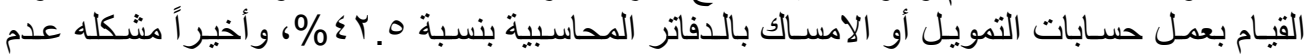
تو افر أماكن للتخزين بنسبة هم حمابت مثل الثنلاجات أو المخازن.

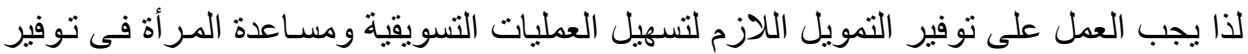

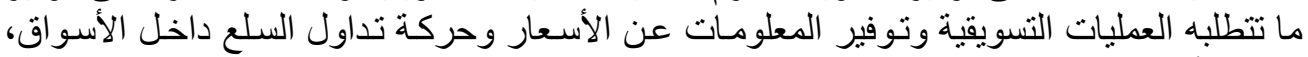

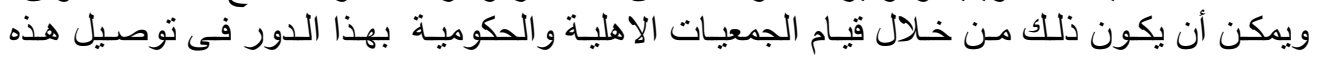

Fayoum J. Agric. Res. \& Dev., Vol.24, No.2, July, 2010 
r.

المعلومـات وتوجيـه نظر المـر أه فـى هذا الخصـوص و العهـل على توفير الأمـاكن التـى تخـزن فيهـا

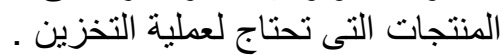

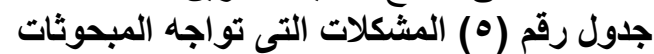

\begin{tabular}{|c|c|c|}
\hline$* * \%$ & العدد * & المشكلات \\
\hline MT.M & $7 \leq$ & عدم توفير التمويل اللازم لعملية التسويق \\
\hline $0 . . \Lambda \mu$ & 71 & عدم معرفة متطلبات السوق \\
\hline $0 . \ldots$ & 7. & مشكلة النقل \\
\hline$\varepsilon 0 . \wedge r$ & 00 & عدم وجود دعاية للمنتج \\
\hline$\varepsilon Y .0$ & 01 & صعوبة القيام بعمل الحسابات و الامساك بالدفاتر المحاسبية \\
\hline ro... & $\varepsilon r$ & عدم تو افر أماكن التخزين \\
\hline
\end{tabular}

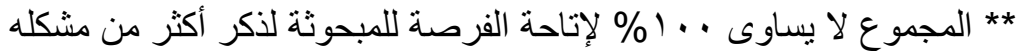

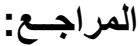

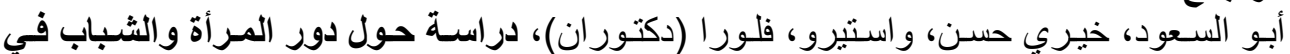

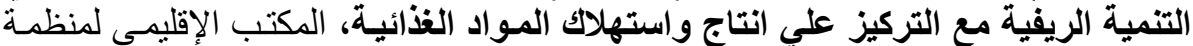

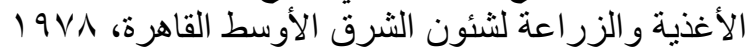

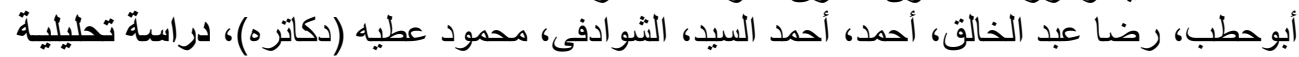

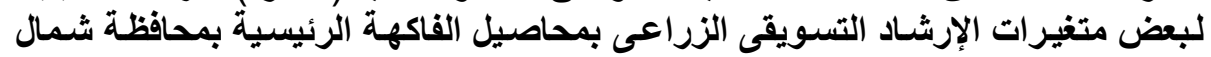

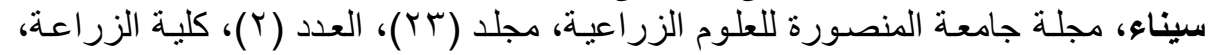

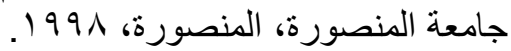
أمال عبد العاطى، دور الإرشاد الزراعى فى تثمية المـرأة الريفيـة، رسـالة دكتور اه، كلية الزر اعـة

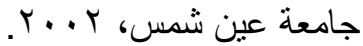

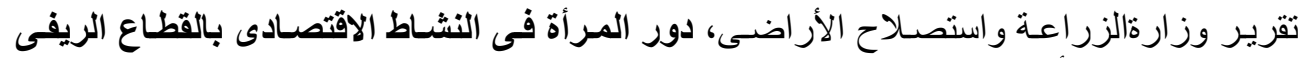

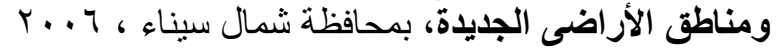

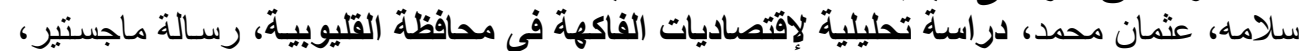

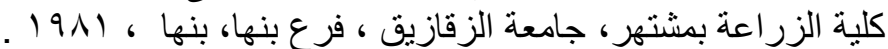

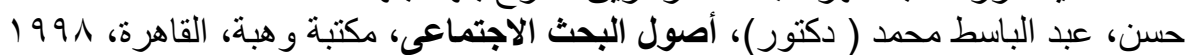

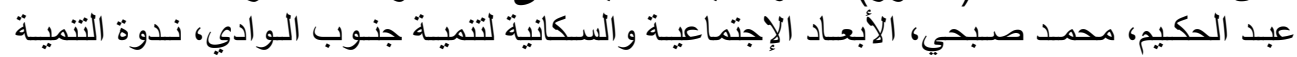

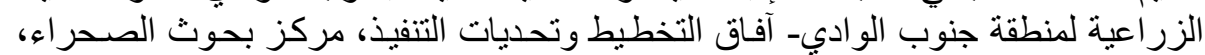

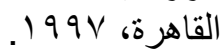

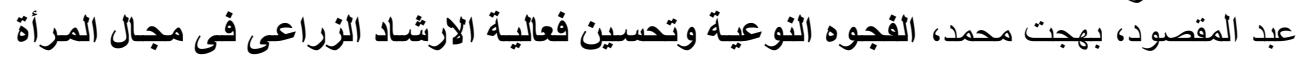

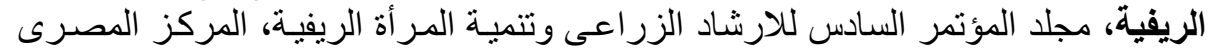

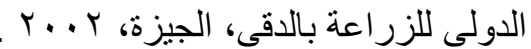

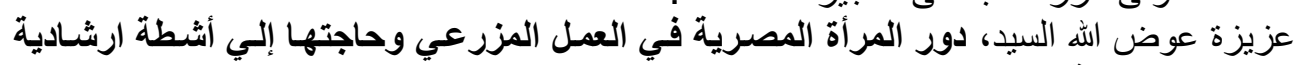

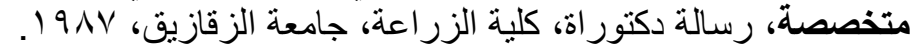

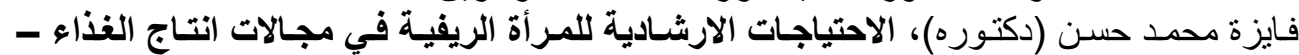

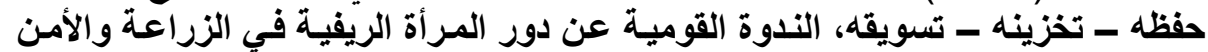

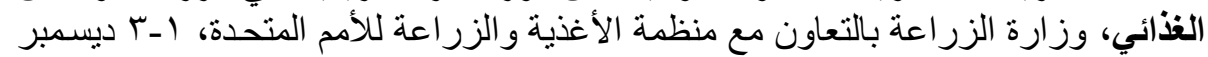

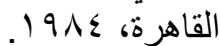

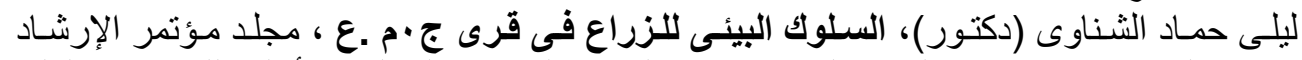

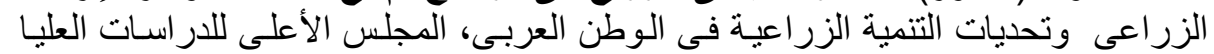

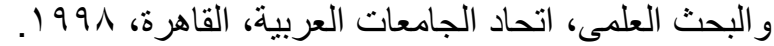
مركز المعلومات ودعم إتخاذ القرار، بيانات غير منشورة، مطروح، 9 ، . ب.

Fayoum J. Agric. Res. \& Dev., Vol.24, No.2, July, 2010 
$\mu$

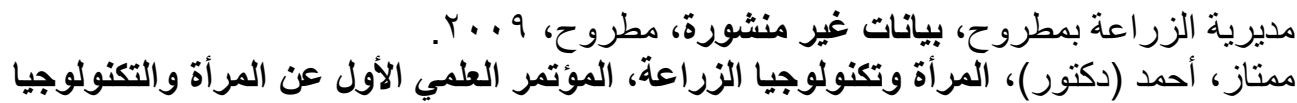

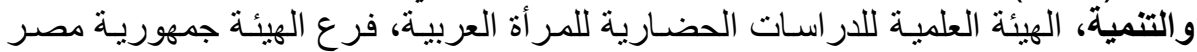

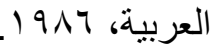

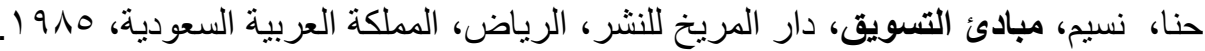

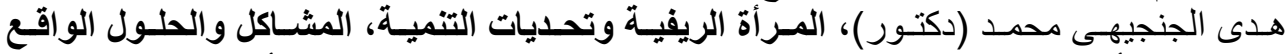

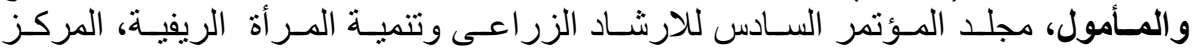

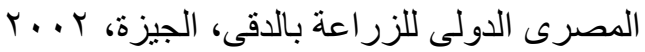

Zimmermann, S.D, The cheese Makers of Kafr Al Bohr, The Role of

Egyptian Women in Animal Husbandry and Dairy Production,

Women and Development Series Egypt, Cairo, 1982.

\section{A STUDY OF SOME BEDWIN WOMEN ACTIVITIES IN MARKTING THEIR LOCAL PRODUCTS IN THE NORTHWEST COAST}

Ashoura Hussien Mohmmed Morsy \& Mostafa Lotfy Abdul-Aziz Mohammed

Department of Rural Sociology -Division of Economic and Social Studies- Desert Research Center - Cairo

\section{ABSTRACT}

The research was conducted to recognize the kinds of local products that women are marketing, markets to the local products, to find out the activities that women undertake to marketing their local products and marketing-related problems.

The study was carried out at the Northwest coast region, Matruh Governorate. Two villages, Alshamama and Awlad AlAmeed, in Al Hamam District were selected to do the study. Data were collected using

Fayoum J. Agric. Res. \& Dev., Vol.24, No.2, July, 2010 
questionnaire forms that were prepared and tested primarily through interviews for both villages. AlShamama village comprised 50 individuals where as Awlad AlAmeed village had 70 ones totaling 120 individuals. Data were statistically analyzed using the (\%) percentage and frequencies.

The study concluded the following results:

Vegetables ranked first with $64.2 \%$ in marketing, followed by poultry with $57.5 \%$ then handcrafts and broidery with $37.5 \%$ and dairy products with $34.2 \%$, where as sheep and goats were of $29.2 \%$ followed by fruit of $21.6 \%$, eggs with $17.0 \%$ and feeders that came last with $13.3 \%$.

Results revealed 7 places where the study sample individuals market their products namely, village market, commissioners, center market, wholesalers then local fairs and in house selling.

Results also showed that bedwin women do 10 activities to market their local products, for most among which were product, transport with $83.33 \%$ followed by gathering information on the product with $69.17 \%$, then presenting the product with $65.83 \%$ connecting to the merchant or the commissioner with $62.5 \%$ and purchasing the raw material for local industry with $33.3 \%$. 